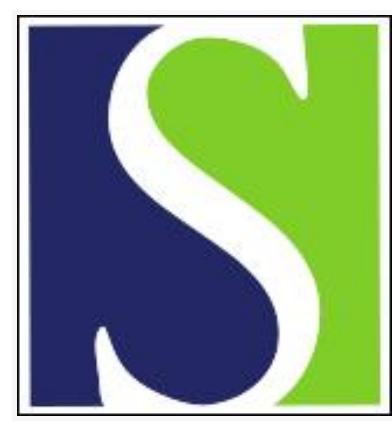

Scand J Work Environ Health 2000;26(3):199-206

https://doi.org/10.5271/sjweh.532

Issue date: Jun 2000

Time to pregnancy and infertility among women with a high intake of fish contaminated with persistent organochlorine compounds

by Axmon A, Rylander L, Strömberg U, Hagmar L

The following article refers to this text: 2002;28(2):124-132

Key terms: contamination; fertility; fish; infertility; PCP; persistent organochlorine compound; polychlorinated biphenyl; polychlorinated dibenzo-p-dioxin; polychlorinated dibenzofuran; time to pregnancy; woman

This article in PubMed: www.ncbi.nlm.nih.gov/pubmed/10901111 


\title{
Time to pregnancy and infertility among women with a high intake of fish contaminated with persistent organochlorine compounds
}

\author{
by Anna Axmon, MSc, ${ }^{1}$ Lars Rylander, DrMedSc, ${ }^{1}$ Ulf Strömberg, PhD, ${ }^{1}$ Lars Hagmar, MD'
}

\begin{abstract}
Axmon A, Rylander L, Strömberg U, Hagmar L. Time to pregnancy and infertility among women with a high intake of fish contaminated with persistent organochlorine compounds. Scand J Work Environ Health 2000;26(3):199206.

Objectives The purpose of this study was to assess the effect of persistent organochlorine compounds through the dietary intake of fatty fish from the Baltic Sea on human fertility.

Methods Information on time to pregnancy, subfertility, and infertility was collected retrospectively by selfadministered questionnaires in 2 cohorts of fishermen's wives from the Swedish east (by the Baltic Sea) and west coasts. In addition to cohort affiliation, current fish consumption and growing up in a fishing village were used as proxies for exposure within the eastcoast cohort.

Results A decreased success (ie, pregnancy) rate and a tendency towards increased subfertility was found for heavy smokers ( $\geq 10$ cigarettes/day) in the eastcoast cohort as compared with the westcoast cohort [success rate ratio $0.66,95 \%$ confidence interval $(95 \%$ CI) $0.49-0.89$; subfertility odds ratio $1.64,95 \%$ CI $0.91-2.91)$. However, internal analyses within the eastcoast cohort did not show that growing up in a fishing village or high current fish consumption decreased the success rate. Eastcoast cohort affiliation showed an increased risk for infertility (odds ratio $2.49,95 \%$ CI $1.05-5.92$ ).

Conclusions The present data give some support for a negative association between exposure to persistent organochlorine compounds and fertility among heavy smokers. However, when the proxy exposure measures are also considered, the findings are not consistent. Better individual exposure assessments should be used before more firm conclusions are drawn.
\end{abstract}

Key terms fertility, polychlorinated biphenyls, polychlorinated dibenzofurans, polychlorinated dibenzo-pdioxins.

For the general Swedish population, the consumption of fatty fish from the Baltic Sea is an important source of exposure to persistent organochlorine compounds such as polychlorinated biphenyls (PCB) and dioxins $(1,2)$. Eastcoast fishermen and their wives have been a relatively highly exposed group; they have reported doubled fish consumption on an average when compared with the general population (2-4). Among these fishermen, higher blood levels of persistent organochlorine compounds have been found than among men from the general population (5). The fishermen's wives had, on the average, approximately $30 \%$ higher $2,2^{\prime}, 4,4^{\prime}, 5,5^{\prime}$-hexachlorobiphenyl (CB-153) plasma levels than women from the Swedish inland (6). Westcoast fishermen and their wives are also high consumers of fish $(2-4,7)$, although contamination from persistent organochlorine compounds in the fish on the west coast has been considerably lower than on the east coast (7). Higher blood levels of persistent organochlorine compounds have been found in eastcoast fishermen than in westcoast fishermen (5).

Our previous studies of fishermen's wives have shown an association between a high dietary intake of Baltic Sea fish contaminated with persistent organochlorine compounds and low birthweight $(4,8,9)$. Furthermore, women from the Lake Michigan area, who consumed PCB-contaminated fish, also delivered infants with a somewhat lowered birthweight (10). A negative correlation of plasma levels of dioxins and PCB with birthweight has been observed for delivering mothers from the general Dutch population (11).

PCB exposure to rats has not only been found to reduce mean pup weight, but also the numbers of successful matings and pregnancies (12). Whether a high dietary intake of fish contaminated with persistent

1 Department of Occupational and Environmental Medicine, Institute of Laboratory Medicine, University Hospital, Lund, Sweden.

Reprint requests to: Ms Anna Axmon, Department of Occupational and Environmental Medicine, Institute of Laboratory Medicine, University Hospital, SE-221 85 Lund, Sweden. [E-mail: anna.axmon@ymed.lu.se] 
organochlorine compounds affects human fertility was therefore the main objective of this study. As an indicator of a couple's fertility, time to pregnancy was used. Time to pregnancy is a suitable epidemiologic outcome variable when reproductive risks from environmental exposures are being studied (13).

Fishermen's wives from the Swedish east coast were regarded as an appropriate study population. For relevant comparison a similar cohort from the Swedish west coast was used.

\section{Subjects and methods}

\section{Study cohorts}

Cohorts of fishermen's wives from the Swedish east $(\mathrm{N}=1989)$ and west $(\mathrm{N}=6605)$ coasts were established (14). Questionnaires were sent to all the women in the cohorts, born in 1945 or later (east, $\mathrm{N}=795$; west, $\mathrm{N}=1851)$. The number of respondents was $505(64 \%)$ from the east coast and $1090(59 \%)$ from the west coast. However, some of the respondents did not fill out the questionnaire completely and were therefore excluded from some of the analyses. Included in the analysis of time to first planned pregnancy were 399 and 936 women from the east- and westcoast cohorts, respectively. The corresponding numbers for the analysis of subfertility and infertility were 378 and 819 .

\section{Outcome variables}

The women were asked about relevant risk factors for their first 5 pregnancies. The primary outcome variable, time to pregnancy, was assessed by the question "How many months did it take you to get pregnant?", allowing for an open-ended answer. We also asked "How sure are you about this?", allowing for the answers "completely sure", "fairly sure" and "very unsure".

We allowed each woman to contribute with only 1 pregnancy (the first planned) to avoid interference from a correlation with the time to pregnancy of succeeding pregnancies. Unplanned pregnancies were excluded, as there is no time to pregnancy to be measured if the pregnancy is not planned.

The women were also asked if there had been, at any time, a period of 12 months when they had not gotten pregnant while trying (excluding times that eventually led to a pregnancy and that the woman had accounted for as time to pregnancy). Women who answered yes to this question or reported a time to pregnancy of 12 months or longer for their 5 first pregnancies were defined as subfertile. Women who reported a time to pregnancy of less than 12 months for all their pregnancies and who did not answer yes to the same question were defined as not subfertile. A question was also asked about each woman's total number of children. Subfertile women who answered that they had no children were defined as infertile. Subfertile women with children, and not subfertile women, were defined as not infertile. Women who, when asked, stated that they, or their partners, were clinically sterile due to a disease or medical or surgical treatment (east, $\mathrm{N}=50$; west, $\mathrm{N}=83$ ) were excluded from all the analyses on subfertility and infertility, as were the women who left the question blank (east, $\mathrm{N}=11$; west, $\mathrm{N}=20$ ).

\section{Exposure variables and potential confounders}

In addition to cohort affiliation, 2 other exposure variables were considered for the internal analysis within the eastcoast cohort. One was "growing up in a fishing village", as it was considered an indirect measure of a high consumption of fatty fish from the Baltic Sea during childhood and adolescence (8). The women were also asked about their current consumption of fatty fish from the Baltic Sea fish $(0,1-4,5-14$ or $>14$ meals/month). This information was collected separately for lunch and dinner. Women who never ate fatty Baltic Sea fish were defined as having no exposure $(\mathrm{N}=64)$, and those who ate such fish at least twice a month were considered to have high exposure $(\mathrm{N}=169)$. It was not possible to in clude all the women in these 2 categories.

Smoking habits, expressed as the number of cigarettes per day, were obtained for the period immediately preceding the pregnancy for both the women and their partners. Women with a subfertile period were asked about smoking habits during this period. Data were also collected on the use of oral contraceptives, the average number of daily workhours, shift work, heavy lifting, and coffee consumption for the period previous to the pregnancy. Furthermore, a question was asked to establish whether the partner was, or had been, a fisherman at the time of conception. There were no questions on alcohol consumption and frequency of intercourse since these topics were considered to be too sensitive.

\section{Background characteristics of the cohorts}

There was no difference between the cohorts with regard to either the woman's or her partner's age at conception (refers to the ages of the woman and her partner, respectively, when they conceived in their first planned pregnancy; the median ages in both cohorts were 22 and 26 years for the women and their partners, respectively). Moreover, there was no marked cohort difference in year of conception (medians 1976 and 1977) or the percentage of first parity births ( $88 \%$ and $90 \%$ ). The eastcoast cohort subjects were more likely to have been smokers (table 1), and the eastcoast women had been gainfully employed to a somewhat less extent. Other life-style factors or occupational exposures did not differ between the cohorts. 


\section{Nonrespondents}

For the analysis of nonrespondens, data from one of our previous studies on the cohorts were used (4). For technical reasons, only women who did not share their birthday with anyone else in the same cohort could be used in the analysis of the nonrespondents. We chose to exclude women born before 1955 from our analysis of nonrespondents since these women were more likely to have given birth before 1973, which is the starting year of the Swedish Medical Birth Register (MBR), from which data were originally collected. Consequently, we compared 612 respondents (east, $\mathrm{N}=196$; west, $\mathrm{N}=416$ ) with 297 nonrespondents (east, $\mathrm{N}=94$; west, $\mathrm{N}=203$ ).

The distributions of age were similar for the nonrespondents and respondents in each cohort (east, median 38 and 39; west, median 37 and 36). The percentage of women who had been pregnant at least once or had ever given birth to a low birthweight child $(<2500 \mathrm{~g})$ or a child with malformation(s) differed only marginally between the nonrespondents and respondents, as did smoking habits and the percentage of women gainfully employed.

\section{Statistics}

The Cox regression (SAS version 6.12 PROC PHREG with discrete handling of ties) was employed to estimate the effects of cohort affiliation, growing up in a fishing village, and fatty fish consumption on time to pregnancy. The estimated curves under the Cox model were compared with the Kaplan-Meier curves to ensure that the proportional hazard assumption was reasonable. For each exposure group the success rate (ie, the number of pregnancies per person-month) was considered (the end point, pregnancy, being regarded as success). For the comparison of 2 exposure groups, the success rate ratio (SuRR) and the $95 \%$ confidence interval $(95 \% \mathrm{CI})$ was estimated. Time to pregnancy was censored at 12 months to avoid interference from medical treatment for infertility; the procedure resulted in 129 censored observations (east, $\mathrm{N}=51$; west, $\mathrm{N}=78$ ). In the multivariate Cox regression models we also considered the woman's age at conception, year of birth, average number of workhours per week, smoking habits, parity, and partner's smoking habits.

The effect of cohort affiliation on infertility and subfertility was given by the odds ratio (OR), estimated using an unconditional logistic regression.

\section{Results}

\section{Time to pregnancy}

Cohort affiliation. There was a lower success rate for the eastcoast cohort than for the westcoast cohort (SuRR
Table 1. Life-style and work habits for women from the east $(\mathrm{N}=399)$ and west $(\mathrm{N}=936)$ coasts, with known time to first planned pregnancy.

\begin{tabular}{|c|c|c|c|c|}
\hline \multirow[t]{2}{*}{ Characteristic } & \multicolumn{2}{|c|}{ East coast } & \multicolumn{2}{|c|}{ West coast } \\
\hline & $N$ & $\%$ & $N$ & $\%$ \\
\hline \multicolumn{5}{|l|}{ Smoking habits } \\
\hline Nonsmoker & 196 & 49 & 596 & 64 \\
\hline Smoker, $1-9$ cigarettes/day & 91 & 23 & 190 & 20 \\
\hline Smoker, $10-19$ cigarettes/day & 95 & 24 & 124 & 13 \\
\hline Smoker, $\geq 20$ cigarettes/day & 17 & 4 & 23 & 2 \\
\hline \multicolumn{5}{|l|}{ Partner's smoking habits } \\
\hline Nonsmoker & 132 & 33 & 525 & 56 \\
\hline Smoker. 1-9 cigarettes/day & 72 & 18 & 146 & 16 \\
\hline Smoker, $10-19$ cigarettes/day & 146 & 37 & 183 & 20 \\
\hline Smoker, $\geq 20$ cigarettes/day & 49 & 12 & 78 & 8 \\
\hline \multicolumn{5}{|l|}{ Coffee consumption } \\
\hline Rarely/never & 53 & 13 & 134 & 15 \\
\hline $1-2$ cups/day & 105 & 27 & 287 & 31 \\
\hline $3-4$ cups/day & 157 & 40 & 345 & 38 \\
\hline$\geq 5$ cups/day & 78 & 20 & 152 & 17 \\
\hline \multicolumn{5}{|l|}{ Education } \\
\hline 9 years of compulsory school & 118 & 30 & 295 & 32 \\
\hline Senior high school & 187 & 47 & 444 & 48 \\
\hline University or college & 90 & 23 & 194 & 21 \\
\hline \multicolumn{5}{|l|}{ Workhours } \\
\hline Did not work & 72 & 18 & 112 & 12 \\
\hline Part-time & 66 & 17 & 139 & 15 \\
\hline Full-time & 260 & 65 & 679 & 73 \\
\hline Shift work & 56 & 15 & 128 & 14 \\
\hline Heavy lifting & 136 & 36 & 337 & 38 \\
\hline $\begin{array}{l}\text { First parity birth (ie, no previous } \\
\text { unplanned pregnancies) }\end{array}$ & 352 & 88 & 845 & 90 \\
\hline \multicolumn{5}{|l|}{ Use of oral contraceptives } \\
\hline before conception & 161 & 40 & 350 & 38 \\
\hline Partner working as a fisherman & 262 & 66 & 733 & 80 \\
\hline Grew up in a fishing village & 55 & 14 & 386 & 42 \\
\hline \multicolumn{5}{|l|}{ Consumption of fatty fish } \\
\hline Low & 64 & 22 & 64 & 11 \\
\hline Medium & 62 & 21 & 139 & 23 \\
\hline High & 169 & 57 & 402 & 66 \\
\hline
\end{tabular}

$0.86,95 \%$ Cr $0.75-0.99$ ) (table 2). When the analysis was restricted to women stating that they were very sure about their time to pregnancy, 479 observations (east, $\mathrm{N}=163$; west, $N=316$ ) were lost, but the point estimate of the SuRR changed only marginally, although the confidence intervals became wider due to the smaller number of observations (SuRR 0.89, 95\% CI 0.74-1.07). Moreover, the inclusion of age, parity, workhours, partner's smoking habits, and partner working as a fisherman in the regression models did not change the SuRR estimate noticeably. Year of conception, coffee consumption, use of oral contraceptives before pregnancy, shift work, heavy lifting, and the partner's age at conception did not show any univariate effect on success rate, and therefore these variables were not included in the multivariate analyses.

The relative effect of cohort affiliation was modified by smoking habits. Nonsmokers and light smokers (1- 
9 cigarettes/day) implied similar effect estimates (SuRR $0.96,95 \%$ CI $0.79-1.17$, and $0.94,95 \%$ CI $0.70-1.26$, respectively) and were therefore grouped together. In addition women who smoked $10-19$ cigarettes per day showed similar success rate ratios as those who smoked 20 cigarettes or more per day (SuRR $0.71,95 \%$ CI $0.52-$ 0.98 , and $0.56,95 \%$ CI $0.27-1.16$, respectively) and were therefore defined as a group (heavy smokers). The results of the stratified analysis indicated that the decreased success rate for the eastcoast women was present among the heavy smokers only (SuRR $0.68,95 \% \mathrm{CI}$ $0.51-0.91$ ) (table 2 and figures 1 and 2).
Growing up in a fishing village. Within the eastcoast cohort growing up in a fishing village had a positive effect on the success rate (table 2 ).

Fish consumption. We found no marked effect of high current fish consumption within the eastcoast cohort (table 2). Stratifying by smoking habits changed the results only slightly. The SuRR for the noncategorized women ( $N=62$ ) was also calculated, but no effect was found for this group either (SuRR 1.05, 95\% CI 0.69-1.59),

Table 2. Effects of cohort affiliation, current consumption of Baltic Sea fish, and having grown up in a fishing village on time to first planned pregnancy (1960 - 1997) in cohorts of fishermen's wives from the east $(\mathrm{N}=399)$ and west $(\mathrm{N}=936)$ coast, stratified for smoking habits. Point estimates of the success rate ratio (SuRR), estimated by the discrete Cox regression, with $95 \%$ confidence intervals ( $95 \%$ $\mathrm{Cl}$ ) are given. Since none of the potential confounders (see the text) changed the effect estimate, unadjusted SuRR values are presented

\begin{tabular}{|c|c|c|c|c|c|c|c|c|c|}
\hline & \multicolumn{3}{|c|}{ All women } & \multicolumn{3}{|c|}{ Non or light smokersa } & \multicolumn{3}{|c|}{ Heavy smokers ${ }^{b}$} \\
\hline & $N$ & SuRR & $95 \% \mathrm{Cl}$ & $\mathrm{N}$ & SuRR & $95 \% \mathrm{Cl}$ & $\mathrm{N}$ & SuRR & $95 \% \mathrm{Cl}$ \\
\hline \multicolumn{10}{|c|}{ Cohort affiliation } \\
\hline Westc & 936 & 1 & & 786 & 1 & . & 147 & 1 & \\
\hline East & 399 & 0.86 & $0.75-0.99$ & 287 & 0.95 & $0.81-1.12$ & 112 & 0.68 & $0.51-0.91$ \\
\hline \multicolumn{10}{|c|}{ Fishing villaged } \\
\hline No & 33 & 1 & & 237 & 1 & . & 98 & 1 & \\
\hline Yes & 55 & 1.32 & $0.94-1.86$ & 42 & 1.28 & $0.86-1.89$ & 13 & 1.44 & $0.73-2.84$ \\
\hline \multicolumn{10}{|c|}{ Fish consumptiond } \\
\hline None & 64 & 1 & & 45 & 1 & & 19 & 1 & $\cdot$ \\
\hline Highe & 169 & 1.07 & $0.90-1.27$ & 126 & 1.13 & $0.92-1.39$ & 43 & 0.95 & $0.68-1.32$ \\
\hline
\end{tabular}

a Light smokers $=1-9$ cigarettes/day in the period immediately before pregnancy.

${ }^{b}$ Heavy smokers $=\geq 10$ cigarettes/day in the period immediately before pregnancy.

c Information on smoking habits was missing for 3 westcoast women.

Within the eastcoast cohort only.

e At least 2 meals per month.

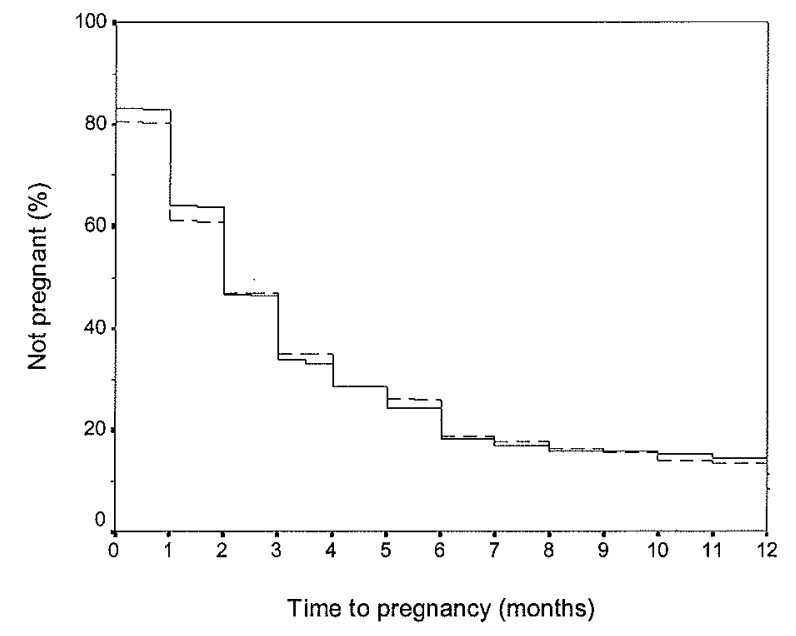

Figure 1. Kaplan-Meier curves of the time to first planned pregnancy based on cohorts of Swedish women from the east $(\mathrm{N}=96$; solid line) and west ( $N=596$; dotted line) coast, restricted to non or light $(0-10$ cigarettes/day in the period immediately preceding pregnancy) smokers. The curves start below $100 \%$ since some of the women stated that they became pregnant after 0 (zero) months of trying.

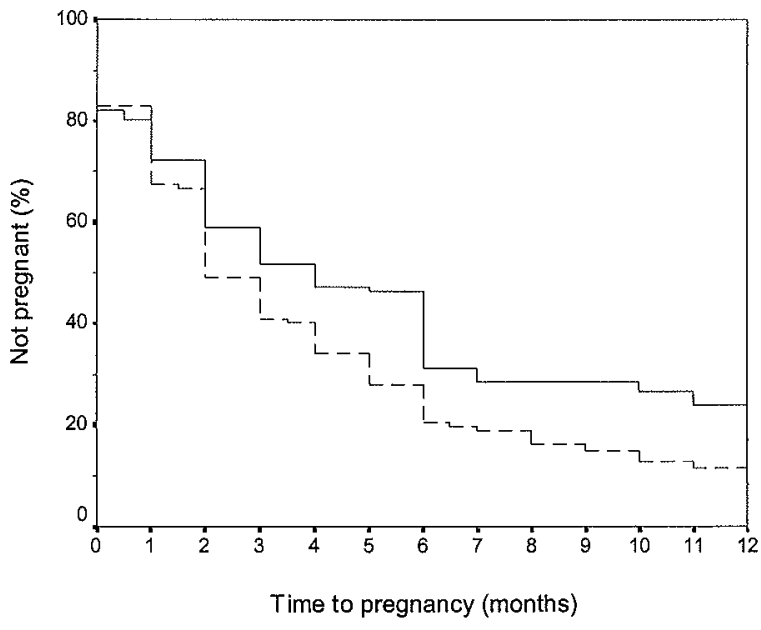

Figure 2. Kaplan-Meier curves of the time to first planned pregnancy based on cohorts of Swedish women from the east ( $N=203$; solid line) and west ( $N=337$; dotted line) coast, restricted to heavy ( $>10$ cigarettes/day in the period immediately preceding pregnancy) smokers. The curves start below $100 \%$ since some of the women stated that they became pregnant after 0 (zero) months of trying. 


\section{Subfertility and infertility}

A somewhat increased risk of subfertility was observed in the eastcoast cohort when it was compared with the westcoast cohort (table 3). As with time to pregnancy, the negative effect of eastcoast-cohort affiliation was stronger for the heavy smokers.

The number of women defined as infertile was very low (11 and 10 subjects in the east- and westcoast cohorts, respectively). Nevertheless, a statistically significant increase in infertility was found for the eastcoast cohort (OR 2.49, 95\% CI 1.05-5.92). No stratification for smoking habits was done due to the low number of infertile women.

According to our definition, younger subfertile women would have a higher risk of being defined as infertile than older women, since younger women were not followed long enough to ensure that they did not achieve a pregnancy later. However, among the women defined as infertile, only 1 woman from each cohort was under 40 years of age (east coast, birth year 1964; west coast, birth year 1966). Removing these 2 women from the analysis changed the results only slightly, as did restricting the analysis to women born in 1960 or before, although the confidence interval grew wider due to the low number of women included in the analysis (OR 2.25, 95\% CI $0.90-5.60$ ).

\section{Discussion}

The results of this study indicate an increase in time to pregnancy for the eastcoast cohort when compared with the westcoast cohort, restricted to heavy smokers. The analyses within the eastcoast cohort did not show that growing up in a fishing village or high current fish consumption increased time to pregnancy.

Joffe has shown the utility of time to pregnancy for assessing conception delay (15), and both Baird et al (13) and Joffe et al (15) have documented the use of the Cox regression model in analyses of time to pregnancy. The use of retrospective self-reports for studying subfertility, and the validity of long-term recall for time to pregnancy has been shown earlier $(16,17)$, as well as the use of time to pregnancy in assessing effects of environmental exposures (13).

In studies of time to pregnancy, the ideal design is prospective, with all women in the study base being included. A retrospective study of women who did get pregnant may be biased since infertile women and unplanned pregnancies are excluded. Hence a comparison of the time trying to conceive, regardless of whether there was success or not, would be more appropriate than a comparison of time to first planned pregnancy. In our
Table 3. Subfertility, defined as at least once having failed to achieve pregnancy within 1 year of trying, in 2 cohorts of fishermen's wives (east=exposed, $\mathrm{N}=338$; west=unexposed, $\mathrm{N}=746$ ). Crude odds ratios $(O \mathrm{R})$ with $95 \%$ confidence intervals $(95 \% \mathrm{CI})$ are given.

\begin{tabular}{|c|c|c|c|c|c|c|}
\hline \multirow[t]{2}{*}{ Cohort } & \multicolumn{2}{|c|}{$\begin{array}{c}\text { All } \\
\text { women }\end{array}$} & \multicolumn{2}{|c|}{$\begin{array}{l}\text { Non or light } \\
\text { smokers }^{a}\end{array}$} & \multicolumn{2}{|c|}{$\begin{array}{c}\text { Heavy } \\
\text { smokers }\end{array}$} \\
\hline & N & $\%$ & $N$ & $\%$ & $N$ & $\%$ \\
\hline West coast ${ }^{\circ}$ & 269 & 36 & 226 & 36 & 39 & 34 \\
\hline East coast & 133 & 39 & 82 & 33 & 49 & 54 \\
\hline OR $(95 \% \mathrm{Cl})$ & \multicolumn{4}{|c|}{$1.15(0.88-1.50)$} & \multicolumn{2}{|c|}{$2.36(1.34-4.16)$} \\
\hline
\end{tabular}

study, the number of unplanned pregnancies was similar in the 2 cohorts, with $87 \%$ of the eastcoast and westcoast women having no unplanned pregnancies. Infertile women were analyzed separately, and a higher frequency was found for the eastcoast cohort. Hence, the exclusion of these women might therefore have biased our results towards the null. However, the number of infertile women was low (11 eastcoast and 10 westcoast women), and thus the impact of including them in the time-to-pregnancy analysis would therefore have been marginal.

With the questionnaire we sent an introductory letter informing the women about the aim of the study. It was clearly stated that we were investigating time to pregnancy as a result of dietary intake of fish contaminated with persistent organochlorine compounds, but it was not specified that the concentration of the compounds was higher in fatty fish from the Baltic Sea. In a previous study, carried out the year before, only $5 \%$ of the women from the eastcoast cohort were aware of the potential health hazards of fish contaminated with persistent organochlorine compounds from the Baltic Sea (8). We therefore believe that possible recall bias in the comparison between the cohorts was of minor concern.

Our study has its major weakness in the low response rate, but the nonrespondent analysis indicated that the low response rate did not introduce selection bias with respect to reproductive outcome, age, or smoking habits. However, reduced fecundity does not necessarily translate into a reduced number of children (18). Hence it is unknown whether or not a selection bias with respect to fecundity was present.

With our questionnaire we assessed the major confounders. We did, however, not ask about alcohol consumption, considering that there was only limited evidence suggesting an effect on time to pregnancy (1921). Recently, however, it has been reported that even a low alcohol intake can be associated with decreased fe- 
cundability $(22,23)$. In our previous studies of fishermen's wives we have found that the alcohol consumption pattern did not differ between the east- and the westcoast cohorts (4), and therefore we do not think that the lack of information on alcohol consumption affected the validity of our results.

It has previously been shown that socioeconomic status varies little between fishermen's wives on the east and west coasts (4). Our cohorts also showed similar distributions for education and workhours. Thus the possible confounding effect of socioeconomic status was reduced by the use of the westcoast cohort for comparison.

Smoking has been described to prolong time to pregnancy by about $25 \%$ to $55 \%(24-26)$. In our study we found a $100 \%$ smoking-related increase in the median time to pregnancy in the eastcoast cohort (4 months for heavy smokers versus 2 months for non or light smokers), but no such increase in the westcoast cohort (2 months for both non or light smokers and heavy smokers). The SuRR for heavy versus non or light smokers was 0.68 and 0.98 within the east- and westcoast cohorts, respectively. This finding indicates that the difference determined for heavy smokers in the east- and westcoast cohorts originated not only from a long median time to pregnancy for heavy-smoking women in the eastcoast cohort, but also from a relatively short median time to pregnancy for heavy-smoking women from the westcoast cohort. Several studies have found a positive correlation between the consumption of noncontaminated fish during pregnancy on one hand and birthweight and duration of pregnancy on the other $(27,28)$, but other reproductive outcomes have not been investigated. Thus whether a high intake of noncontaminated fatty fish is a positive factor for fertility can only be a matter of speculation.

A synergistic interaction between smoking and $\mathrm{PCB}$ on fertility is compatible with the present results. A similar result has been seen when the effect of PCB on birthweight has been examined (4). It should be noted that the birthweight study was performed on the 2 cohorts that provided the basis for the present study, and the synergistic effects found can therefore not be regarded as independent. Other studies on reproductive outcome have failed to show any interaction between PCB and smoking $(29,30)$.

One concern regarding our findings should be if the heavy smokers on the east coast smoked more cigarettes per day than the heavy smokers on the west coast. However, similar effect estimates for the "cohort variable" were obtained for the women who smoked 10-19 and $\geq 20$ cigarettes a day, respectively. Thus the observed cohort difference is not likely to have arisen from residual confounding from smoking.

The estimated current consumption of fatty fish from the Baltic Sea was not associated with an increased time to pregnancy within the eastcoast cohort. Thus no support was obtained for our hypothesis. Moreover, among women with a dietary intake of contaminated fish from Lake Ontario, no adverse effect of current fish consumption on time to pregnancy was found (31). The estimated current dietary exposure to persistent organochlorine compounds through fish consumption was comparable between groups of high consumers from the Baltic Sea and the Lake Ontario regions (32). It should, however, be considered that present fish consumption is not necessarily a good proxy for consumption relevant for conception, when it is considered that the dietary intake of Baltic Sea fish has decreased since the early 1970s (4). We have abstained from using the recall of fish intake during pregnancy, since we have previously shown a low reliability for the long-term dietary recall of such food items (33).

For the eastcoast cohort, "growing up in a fishing village" was used as a proxy measure of high consumption of fatty fish from the Baltic Sea during childhood and adolescence. The results did not support our hypothesis of a prolonged time to pregnancy among women with this childhood exposure. On the contrary, a tendency toward a beneficial effect from the assumed hazardous exposure was seen. It should, however, be born in mind that very few eastcoast women had grown up in a fishing village, and hence the confidence interval for the risk estimate became rather wide. If true, a possible interpretation of the contrasting results of an adverse effect of being a fisherman's spouse from the east coast and the apparent beneficial effect from growing up in an eastcoast fishing village may be that some constituents in fatty fish (eg, polyunsaturated fatty acids) may be beneficial for germ-cell development during fetal life, whereas some other constituents (eg, persistent organochlorine compounds) may have an adverse effect on fertility during adult life.

Infertility was significantly higher in the eastcoast cohort (3\% among the eastcoast women versus $1 \%$ among the westcoast women). In a study on Swedish midwives $3.9 \%$ of the respondents reported having tried to achieve pregnancy without success (34). Infertility of even greater magnitude has been found in other studies $(35,36)$. These numbers point to the possibility that there may be a low infertility frequency among the westcoast women, rather than a high one among the women from the east coast.

In summary, an increase in time to pregnancy was found for heavily smoking women in the eastcoast cohort when they were compared with the westcoast cohort. The internal analyses within the eastcoast cohort failed to support our hypothesis that a high intake of fatty fish contaminated with persistent organochlorine compounds from the Baltic Sea would increase time to pregnancy, although the result may have been due to unsatisfactory exposure assessments. For a further assessment 
of the relation between the dietary intake of contaminated fish and time to pregnancy, an individual exposure biomarker (eg, CB-153) should be used.

\section{Acknowledgments}

The authors thank Gunnar Ahlborg, Jr, and Lennart Bodin for their fruitful discussions. We also thank Gudrun Persson, Ulrika Wallin, and Thérèse Mikoczy for their valuable help with the distribution of the questionnaires and the data entry.

This work was financed by grants from the Swedish Medical Research Council, the Swedish National Environmental Protection Board, the Swedish Foundation for Strategic Environmental Research, and the Medical Faculty, Lund University.

\section{References}

1. Asplund L, Svensson B-G, Nilsson A, Eriksson U, Jansson B, Jensen $S$, et al. Polychlorinated biphenyls, 1,1,1-trichloro-2,2bis(p-chlorophenyl)ethane (p,p'-DDT) and 1,1-dichloro-2,2bis(p-chlorophenyl)ethylene ( $\left.\mathrm{p}, \mathrm{p}^{\prime}-\mathrm{DDE}\right)$ in human plasma related to fish consumption. Arch Environ Health 1994; 49:477-86.

2. Svensson B-G, Nilsson A, Hansson M, Rappe C, Åkesson B, Skerfving S. Exposure to dioxins and dibenzofurans through the consumption of fish. N Engl J Med 1991;324:8-12.

3. Hagmar L, Lindén K, Nilsson A, Norrving B, Åkesson B, Schütz A, et al. Cancer incidence and mortality among Swedish Baltic Sea fishermen. Scand J Work Environ Health 1992;18:217-24.

4. Rylander L, Strömberg U, Hagmar L. Decreased birthweight among infants born to women with a high dietary intake of fish contaminated with persistent organochlorine compounds. Scand J Work Environ Health 1995;21:368-75.

5. Svensson B-G, Nilsson A, Jonsson E, Schütz A, Åkesson B, Hagmar L. Fish consumption and exposure to persistent organochlorine compounds, mercury, selenium and methylamines among Swedish fishermen. Scand J Work Environ Health 1995;21:96-105.

6. Rylander L, Dyremark E, Strömberg U, Östman C, Hagmar L. The impact of age, lactation and dietary habits on $\mathrm{PCB}$ in plasma in Swedish women. Sci Total Environ 1997;207:5561.

7. Bergqvist P, Bergek S, Hallbäck H, Rappe C, Slorach S. Dixoins in cod and herring from the seas around Sweden. Chemosphere 1989:513 - 516.

8. Rylander L, Strömberg U, Hagmar L. Dietary intake of fish contaminated with persistent organochlorine compounds in relation to low birthweight. Scand $\mathbf{J}$ Work Environ Health 1996;22:260-6.

9. Rylander L, Strömberg U, Dyremark E, Östman C, NilssonEhle P, Hagmar L. Polychlorinated biphenyls in blood plasma among Swedish female fish consumers in relation to low birth weight. Am J Epidemiol 1998;147:493-502.
10. Fein GG, Jacobson JL, Jacobson SW, Schwartz PM, Dowler JK. Prenatal exposure to polychlorinated biphenyls: effects on birth size and gestational age. J Pediatr 1984;105:315-20.

11. Patandin S, Koopman-Esseboom C, de Ridder MA, Weisglas-Kuperus N, Sauer PJ. Effects of environmental exposure to polychlorinated biphenyls and dioxins on birth size and growth in Dutch children. Pediatr Res 1998;44:538 - 45.

12. Brouwer A, Ahlborg UG, Van den Berg M, Birnbaum LS, Boersma ER, Bosveld B, et al. Functional aspects of developmental toxicity of polyhalogenated aromatic hydrocarbons in experimental animals and human infants. Eur J Pharmacol Environ Toxicol Pharmacol Section 1995:1- 40.

13. Baird DD, Wilcox AJ, Weinberg CR. Use of time to pregnancy to study environmental exposures. Am J Epidemiol 1986;124:470-80.

14. Rylander L, Hagmar L. Mortality and cancer incidence among women with a high consumption of fatty fish contaminated with persistent organochlorine compounds. Scand J Work Environ Health 1995;21:419-26.

15. Joffe $M$. Time to pregnancy: a measure of reproductive function in either sex: Asclepios Project. Occup Environ Med 1997;54:289-95.

16. Joffe M, Villard L, Li Z, Plowman R, Vessey M. Long-term recall of time-to-pregnancy. Fertil Steril 1993;60:99-104.

17. Joffe M. Feasibility of studying subfertility using retrospective self reports. J Epidemiol Community Health 1989; 43:268-74.

18. Bonde JP, Kolstad H. Fertility of Danish battery workers exposed to lead. Int J Epidemiol 1997;26:1281-8.

19. Olsen J. Cigarette smoking, tea and coffee drinking, and subfecundity. Am J Epidemiol 1991;133:734-9.

20. Joffe M, Li Z. Male and female factors in fertility. Am J Epidemiol 1994;140:921—9.

21. Florack EI, Zielhuis GA, Rolland R. Cigarette smoking, alcohol consumption, and caffeine intake and fecundability. Prev Med 1994;23:175-80.

22. Jensen TK, Hjollund NHI, Henriksen TB, Scheike T, Kolstad $\mathrm{H}$, Giwercman A, et al. Does moderate alcohol consumption affect fertility? Follow up study among couples planning first pregnancy. BMJ 1998;317:505-10.

23. Hakim RB, Gray RH, Zacur H. Alcohol and caffeine consumption and decreased fertility. Fertil Steril 1998;70:6327.

24. Jensen TK, Schaumburg I, Boldsen J. Cigaretrygning og ventetid till graviditet hos danske apoteksassistenter. Ugeskr Laeger 1992;154:1360-3.

25. Bolumar F, Olsen J, Boldsen J. Smoking reduces fecundity: a European multicenter study on infertility and subfecundity: the European Study Group on Infertility and Subfecundity. Am J Epidemiol 1996;143:578-87.

26. Curtis KM, Savitz DA, Arbuckle TE. Effects of cigarette smoking, caffeine consumption, and alcohol intake on fecundability. Am J Epidemiol 1997;146:32 — 41.

27. Olsen SF, Grandjean P, Weihe P, Videro T. Frequency of seafood intake in pregnancy as a determinant of birth weight: evidence for a dose dependent relationship. J Epidemiol Community Health 1993;47:436-40.

28. Odent MR, McMillan L, Kimmel T. Prenatal care and sea fish. Eur J Obstet Gynecol Reprod Biol 1996;68:49-51.

29. Dar E, Kanarek MS, Anderson HA, Sonzogni WC. Fish consumption and reproductive outcomes in Green Bay, Wisconsin. Environ Res 1992;59:189-201.

30. Mendola P, Buck GM, Vena JE, Zielezny M, Sever LE. Consumption of PCB-contaminated sport fish and risk of 
spontaneous fetal death. Environ Health Perspect 1995; 103:498-502.

31. Buck GM, Sever LE, Mendola P, Zielezny M, Vena JE. Consumption of contaminated sport fish from Lake Ontario and time-to-pregnancy: New York State angler cohort. Am J Epidemiol 1997;146:949-54.

32. Ahlborg U, Hanberg A, Kenne K. Risk assessment of polychlorinated biphenyls (PCBs). Copenhagen: Nordic Council of Ministers, 1992. Nord 1992:26.

33. Rylander L, Strömberg U, Hagmar L. Agreement between reported fish consumption obtained by two interviews and its impact on the results in a reproduction study. Eur J Epidemiol
1998;14:93-7.

34. Ahlborg G Jr, Axelsson G, Bodin L. Shift work, nitrous oxide exposure and subfertility among Swedish midwives. Int $\mathrm{J}$ Epidemiol 1996;25:783-90.

35. Högberg U, Sandström A, Nilsson NG. Reproductive patterns among Swedish women born 1936 - 1960. Acta Obstet Gynecol Scand 1992;71:207-14.

36. Wulff $M$, Högberg U, Stenlund $H$. Infertility in an industrial setting - a population-based study from Northern Sweden. Acta Obstet Gynecol Scand 1997;76:673-9.

Received for publication: 10 February 1999 